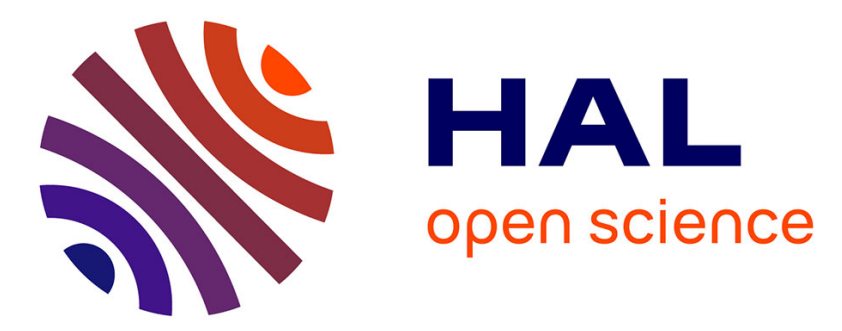

\title{
Energy release rate of the fiber/matrix interface crack in UD composites under transverse loading: debond-debond and debond-free boundary interactions
}

\author{
Luca Di Stasio, Janis Varna, Zoubir Ayadi
}

\section{- To cite this version:}

Luca Di Stasio, Janis Varna, Zoubir Ayadi. Energy release rate of the fiber/matrix interface crack in UD composites under transverse loading: debond-debond and debond-free boundary interactions. 2019. hal-02187429

\author{
HAL Id: hal-02187429 \\ https://hal.science/hal-02187429
}

Preprint submitted on 17 Jul 2019

HAL is a multi-disciplinary open access archive for the deposit and dissemination of scientific research documents, whether they are published or not. The documents may come from teaching and research institutions in France or abroad, or from public or private research centers.
L'archive ouverte pluridisciplinaire HAL, est destinée au dépôt et à la diffusion de documents scientifiques de niveau recherche, publiés ou non, émanant des établissements d'enseignement et de recherche français ou étrangers, des laboratoires publics ou privés.

\section{(ㅇ)(1) $\$$}

Distributed under a Creative Commons Attribution - NonCommercial - NoDerivatives| 4.0 


\title{
Energy release rate of the fiber/matrix interface crack in UD composites under transverse loading: debond-debond and debond-free boundary interactions
}

\author{
Luca Di Stasio ${ }^{\mathrm{a}, \mathrm{b}, 1}$, Janis Varna $^{\mathrm{b}}$, Zoubir Ayadi $^{\mathrm{a}}$ \\ ${ }^{a}$ Université de Lorraine, EEIGM, IJL, 6 Rue Bastien Lepage, F-54010 Nancy, France \\ ${ }^{b}$ Luleå University of Technology, University Campus, SE-97187 Luleå, Sweden
}

\begin{abstract}
The effects of crack shielding, finite thickness of the composite and fiber content on fiber/matrix debond growth in thin unidirectional composites are investigated analyzing Representative Volume Elements (RVEs) of different ordered microstructures. Debond growth is characterized by estimation of the Energy Release Rates (ERRs) in Mode I and Mode II using the Virtual Crack Closure Technique (VCCT) and the J-integral. It is found that increasing fiber content, a larger distance between debonds in the loading direction and the presence of a free surface close to the debond have all a strong enhancing effect on the ERR. The presence of fully bonded fibers in the composite thickness direction has instead a constraining effect, and it is shown to be very localized. An explanation of these observations is proposed based on mechanical considerations.

Keywords: Polymer-matrix Composites (PMCs), Thin-ply, Energy Release Rate, Debonding, Finite Element Analysis (FEA)
\end{abstract}

\section{Introduction}

Stimulated by the ever more stringent requirements in terms of weight and mechanical performances of the aerospace industry, in recent years the composite community has returned its attention to the mechanisms of intralam${ }_{5}$ inar crack initiation with a focus on thin-ply laminates. Alternative design

\footnotetext{
${ }^{1}$ Corresponding author: luca.di.stasio@ltu.se .
} 
approaches are now considered based on this non-conventional laminate in applications ranging from cryogenic pressure vessels [1], to airplanes' wings [2], and even reusable space launchers [3].

Thin-ply laminates are the result of a technological innovation, the spread tow technology, which consists in opening or spreading the tows, in which fibers (carbon, glass, aramid, basalt among others) are usually shipped in, into very thin tapes used for laminate production. Ply thicknesses of less than $50 \mu \mathrm{m}$ can nowadays be mass-produced, and record thicknesses of around $20-25 \mu \mathrm{m}$, or $\sim 4-5$ times the average fiber's diameter, have been achieved. In its current form the technique, sometimes referred to as "FUKUI method", was firstly proposed towards the end of the 1990s 4] and perfected in the subsequent decade [5, 6].

Several experimental investigations on thin ply laminates have highlighted their main properties [7, 8, [9, 10, 11, 12, 13: increased fiber content; more uniform packing of fibers; delay and even suppression of intralaminar cracking (called also transverse-, matrix- or micro-cracking) and delamination. A very insightful work documenting how these phenomena are affected by the morphology of thin-ply laminates is the microscopic study of Saito \& al. [14, which focuses on the effect of ply thickness on the onset and propagation of intralaminar crack25 ing. In their investigation, tensile tests were performed on carbon fiber/epoxy $\left[0_{2}, 90_{n}, 0_{2}\right]$ thin-ply laminates for $n=1,2,4$ and the crack density was measured with a digital microscope at several levels of applied tensile strain in the range between $0 \%$ and $1.5 \%$. Furthermore, they performed microscopic observations on the specimen's edge at each level of strain. They observed the onset of fiber/matrix interface cracks (referred to as debonds in the following) at lower levels of strain in thinner plies, while at the same time coalescence of debonds and through-the-thickness propagation of transverse cracks in thin plies were delayed and even suppressed as ply thickness decreased. In particular, they reported the first onset of debonds at $0.4 \%$ for $n=1,2$ and $0.7 \%$ for $n=4$. For

${ }_{35} n=1$, however, at $\varepsilon=1.5 \%$ coalescence of debonds had started to take place but the crack had not completely propagated through the thickness, while for 
$n=2$ and $n=4$ the latter alreay happened at a value of strain respectively of $1.3 \%$ and $1 \%$. Our inability to explain these observations with the currently accumulated knowledge demonstrates the necessity of further investigation of interactions between debonds and studies of the constraining (or accelerating) effect of presence of bonded fibers, free and constrained boundaries in the vicinity of a partially debonded fiber.

Early studies on the effect of ply thickness on the onset and propagation of transverse cracks were conducted on glass fiber/epoxy cross-ply laminates by Bailey, Parvizi and collaborators [15, 16, 17, who firstly observed the beneficial effect of thickness reduction on the delay of transverse cracking. They furthermore pointed the attention to the appearance of debonds at the fiber/matrix interface and their subsequent coalescence as the mechanism at the origin of transverse cracks [18]. Moreover, they identified the main mechanical driver of the damage process in the mismatch of elastic properties, and particularly of Poisson's ratios, between fibers and matrix 19. A full understanding of damage onset and propagation in thin-ply laminates thus requires comprehension of the mechanisms governing its very first stage, i.e. the fiber/matrix interface crack. First results were obtaned through analytical models in the case of a 55 single fiber with an arc crack (debond) in an infinite matrix under transverse tension by England [20] and Perlman \& Sih [21], who obtained the stresses at the interface and calculated the stress intensity factors at the crack tip, and by Toya 22, who evaluated the Energy Release Rate (ERR). Drawing upon the results for the straight bi-material interface crack by Comninou [23], the effect of crack face contact in fiber-matrix debonding was investigated in 24, 25. In [26], it was showed in terms of ERR why the case of a single asymmetric debond is more likely to be observed under remote transverse tension than two symmetric debonds on the same fiber. The effect of different types and combinations of loads on debonding have been studied for the single fiber model: ${ }_{65}$ compression [27, residual thermal stresses [28, and biaxial configurations with different combinations of tension and compression [29, 30. The effect of the presence of nearby bonded fibers on the debonding of a fiber embedded in an 
infinite matrix has been studied under uniaxial transverse tension [31, biaxial tension [32] and uniaxial transverse compression [33. The effect of inter-fiber distance on debond growth has been studied for a partially debonded fiber at the center of a hexagonal cluster inside a homogenized UD composite in the case of fully bonded neighbouring fibers [34] and of two partially debonded fibers out of the surrounding six [35]. An understanding of crack shielding and finite ply thickness effects on debond growth in non-homogenized microstructural models of UDs seems thus to be lacking: this is the problem that we want to address in the present work. Mode I and Mode II energy release rates will be analyzed using stress fields calculated with the FEM for a variety of Repeating Unit Cell (RUC) of the composite with square packing of fibers under transverse tensile loading. These RUCs represent composites with different distances between partially debonded fibers and a varying number of bonded fibers between them, which allows to study the effect of crack shielding on the ERR. In the ply thickness direction, the varying number of perfectly bonded fiber rows exposes the effect of the proximity of the free boundary of the composite on debond growth. Finally, using coupling of thickness direction displacements on horizontal boundaries of the RUC, the accelerating effect of the interaction between debonds of fibers located on the same vertical line is studied.

\section{RVE models \& FE discretization}

\subsection{Introduction \& Nomenclature}

In this paper, we analyze debond development in unidirectional (UD) composites subjected to in-plane transverse tensile loading. The interaction between debonds in UD composites is studied developing models of different Repeating Unit Cells (RUC) of laminates (see Fig. 1 to Fig. 3) where only the central fiber in the cell has a damage in the form of a fiber/matrix interface crack (debond). The composite RUC may be repeating in the in-plane transverse direction only (representing an ultra-thin composite) or repeating also in the composite thickness direction, representing an infinite composite in a limiting 
case. Thus, the conditions at the UD composite's upper and lower boundaries are one of the parameters for the investigation. The used RUCs allow for considering the composite with debonds as a sequence of stacked damaged and undamaged fiber rows, each row with only one fiber in the thickness direction. Since all of these RUCs feature regular microstructures with fibers placed according to a square-packing configuration, they are Representative Volume Elements (RVE) of composites with a certain distribution of debonds. Introducing in-plane coordinates $x$ and $y$, where $x$ is in the transverse direction of the UD composite under consideration, the strain in the $y$-direction due to a load in the $x$-direction is small, caused in turn by the very small minor Poisson's ratio of the UD composite. Additionally, debonds are considered to be significantly longer in the fiber direction than in the arc direction. Therefore, we use $2 \mathrm{D}$ models under the assumption of plane strain, defined in the $x-z$ section of the composite. Thus, the analysis presented applies to long debonds, with a focus on understanding the mechanisms of growth along their arc direction. The composites are subjected to transverse tensile strain, applied as a constant displacement in the $x$-direction along the vertical boundary of the RUC as shown in Figures 1 to 4 . As the models are differentiated by the number of rows of fibers and by the spacing between debonds along the vertical and horizontal directions, the corresponding RUCs can be distinguished from each other based on the number $n$ of fibers in the horizontal direction and $k$ in the vertical direction. Furthermore, the horizontal surfaces can be either free or vertical displacement coupling can be applied. We thus introduce a common notation $n \times k-$ free and $n \times k-$ coupling to denote a RUC with $n \times k$ fibers and, respectively, a free upper surface or with kinematic coupling applied to it. The specific combinations of particular choices of $n, k$, and boundary conditions are detailed in Section 2.2 together with the description of the corresponding models of damaged composite they are representing. 


\subsection{Models of Representative Volume Element (RVE)}

The first two models feature, as shown in Fig. 1, an ultra-thin UD laminate with only one row of fibers across its thickness, $k=1$. This is quite an extreme model from the microstructural point of view; however, it allows to focus the analysis on the interaction between debonded fibers placed along the $\mathrm{x}$-direction. Furthermore, as the horizontal surfaces are considered free, the interaction is stronger in this case than in any other, making the trends very clear and the predictions of this model rather conservative. In retrospective, if only 20 years ago such a model would have been considered too abstracted from the physical reality, the recent advancements in the spread tow technology make this approach appealing also as a limiting case for practical considerations.

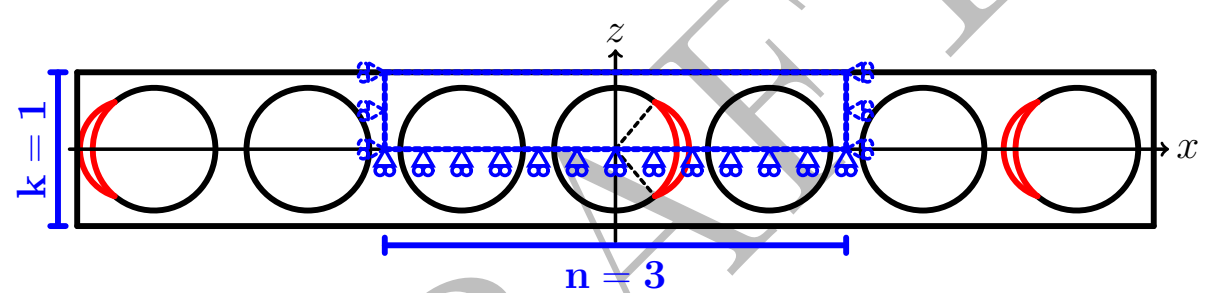

(a) Single row of fibers with a debond appearing every $n$ fibers: model $n \times 1-$ free $(n=3$ in the figure).

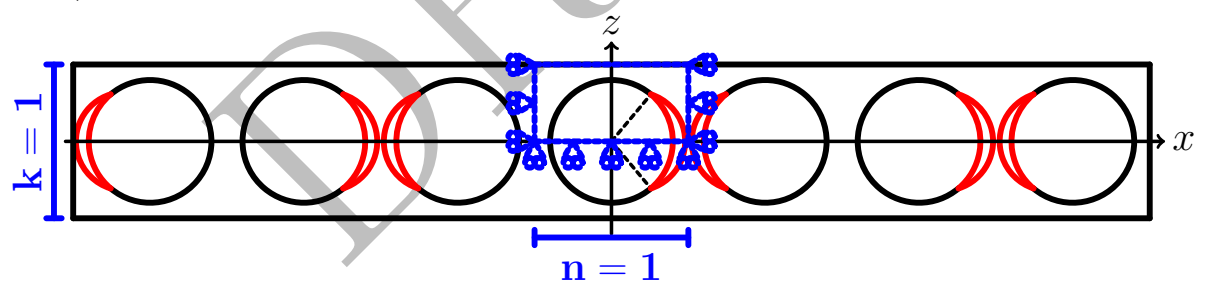

(b) Single row of fibers with debonds appearing on each fiber: model $1 \times 1-$ free

Figure 1: Models of ultra-thin UD composites with a single "row" of fibers and debonds repeating at different distances.

In the sub-model of Fig. 1a, every $n^{\text {th }}$ fiber in the composite is partially debonded on alternating sides of the fiber. The symmetries of the model allow the use of the upper part of the RUC, as highlighted in Fig. 1 to 3 Following the notation introduced in Section 2.1, we will refer to this model as $n \times 1-$ free. 
sides and the corresponding RUC contains only one fiber. We will refer to this model as $1 \times 1-$ free.

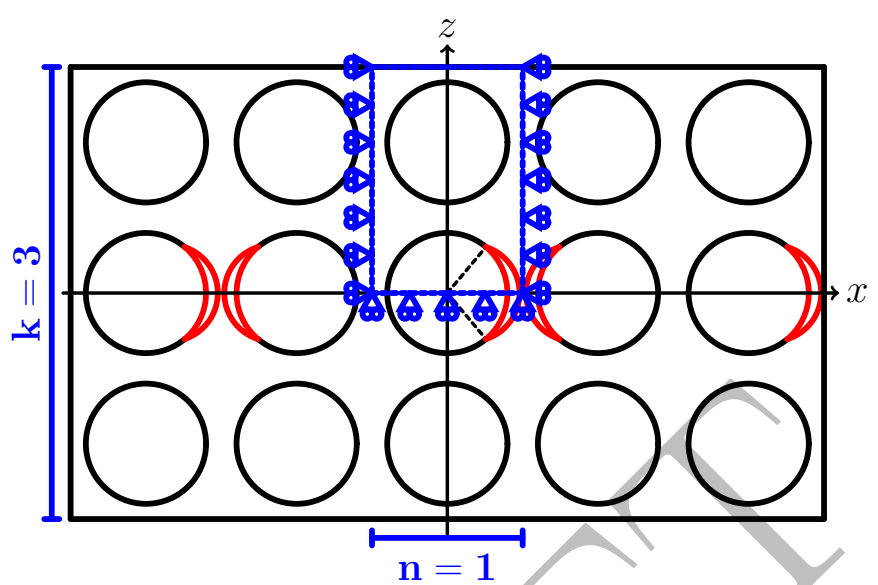

(a) Multiple rows of fibers with debonds appearing on each fiber beloging to the central row: model $1 \times k-\operatorname{free}(k=3$ in the figure).

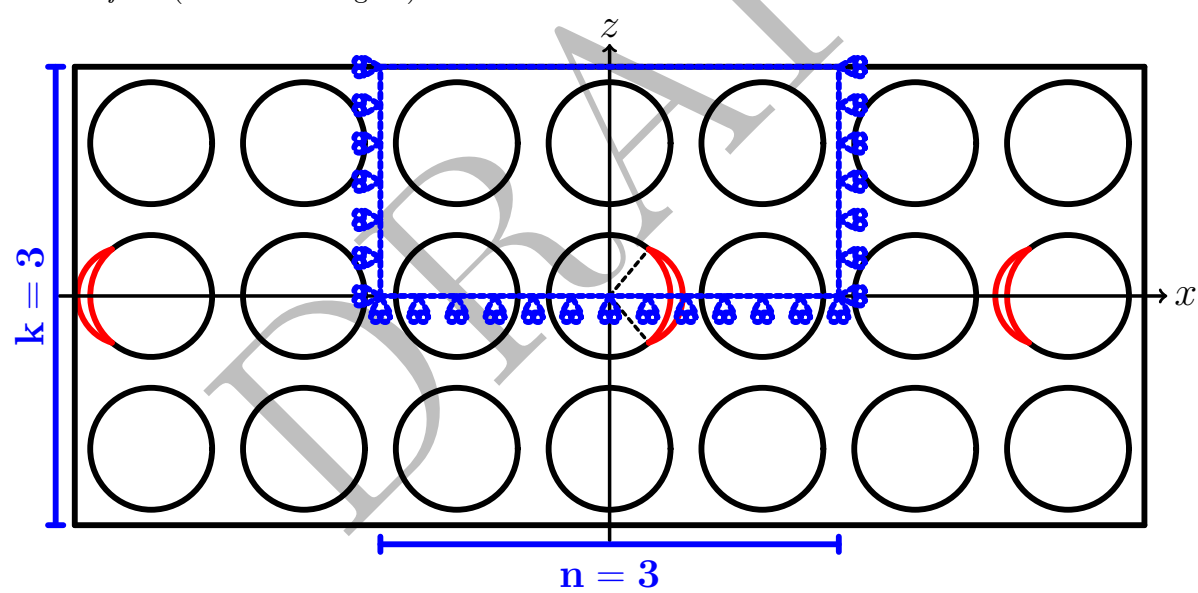

(b) Mutiple rows of fibers with a debond appearing every $n$ fibers within the central row: model $n \times k-$ free $(n=3$ and $k=3$ in the figure).

Figure 2: Models of UD composites with different "rows" of fibers and debonds repeating at different distances.

The second set of models in Fig. 2 and Fig. 3 considers laminates with multiple rows of fibers across the thickness: a finite number of rows in the first 145 two sub-models in Fig. 2. an infinite number in the model of Fig. 3 . In Fig. 2a. 
the RUC contains $n=1$ fiber in the x-direction, $k$ fibers across the thickness and the central fiber is debonded. This model will be referred to in the following as $1 \times k-$ free. Thinking in terms of rows, in this model we have a central row where each fiber is debonded. This row is surrounded from each side by $(k-1) / 2$ rows with perfectly bonded fibers. In the sub-model in Fig. 2b, each $n^{\text {th }}$ fiber in the central row is debonded and this row is surrounded by $(k-1) / 2$ rows of undamaged fibers from each side. We will refer to this model as $n \times k-$ free (because the horizontal boundary of the RUC is free of any constraint).

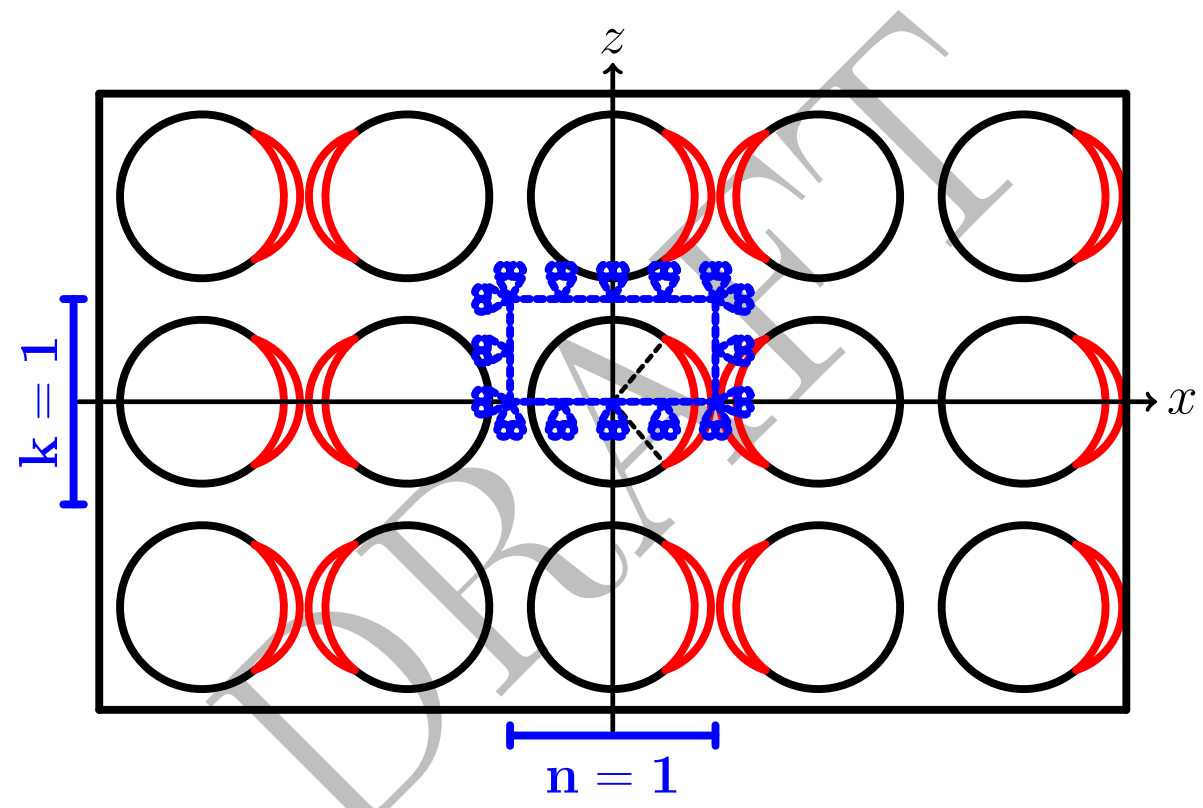

Figure 3: Model of UD composites with an infinite number of "rows" of fibers and debonds appearing on each fiber: model $1 \times 1-$ coupling .

Finally, the model in Fig. 3 represents an UD composite with an infinite number of rows; all of them with partially debonded fibers. As all fibers have debonds, the corresponding RUC is made of a single partially debonded fiber with kinematic coupling conditions applied to the upper boundary to assure periodicity. This model is referred to as $1 \times 1-$ coupling. 


\subsection{Finite Element (FE) discretization}

160

the Abaqus environment, a commercial FEM package [36]. The length $l$ and height $h$ of the model are determined by the number of fibers $n$ in the horizontal direction and $k$ across the thickness (see 2.2) according to Eq. 1 .

$$
l=2 n L \quad h=k L
$$

where $2 L$ is the length of a one-fiber unit, see Fig. 4, defined as a function of the fiber volume fraction $V_{f}$ and the fiber radius according to

$$
L=\frac{R_{f}}{2} \sqrt{\frac{\pi}{V_{f}}} .
$$

The fiber radius $R_{f}$ is assumed to be the same for each fiber in the model and equal to $1 \mu \mathrm{m}$. The latter value is not physical and it has been chosen for simplicity. It is worth to note at this point that, in a linear elastic solution as the one presented here, the ERR is proportional to the geometrical dimensions and recalculation of the ERR for fibers of any size, thus, requires a simple multiplication. Furthermore, notice that the relationships in Eqs. 1 and 2 ensure that the local and global $V_{f}$ are everywhere equal.

The debond is placed symmetrically with respect to the $x$ axis (see Fig. 4) and we characterize it with an angular size of $\Delta \theta$ (the full debond size is thus $2 \Delta \theta)$. For large debond sizes $\left(\geq 60^{\circ}-80^{\circ}\right)$, a region of variable size $\Delta \Phi$ appears at the crack tip in which the crack faces are in contact and slide on each other. Due to its appearance, frictionless contact is considered between the two crack faces to allow free sliding and avoid interpenetration. Symmetry with respect to the $x$ axis is applied on the lower boundary. The upper boundary is in general 180 free, except for the model $1 \times 1-$ coupling (Fig. 3) which requires kinematic coupling of vertical displacements also on the upper side. Kinematic coupling on the $x$-displacement is applied along the left and right sides of the model in the form of a constant $x$-displacement $\pm \bar{\varepsilon}_{x} l$, corresponding to transverse strain $\bar{\varepsilon}_{x}$ equal to $1 \%$. 


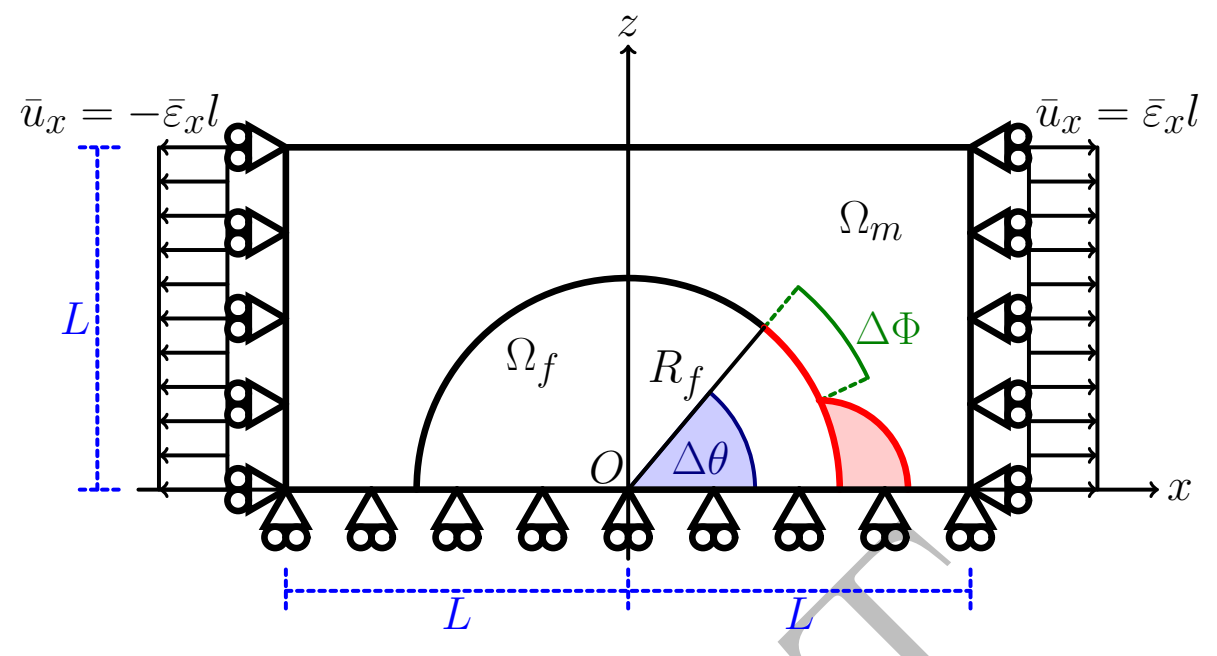

Figure 4: Schematic of the model with its main parameters.

Table 1: Summary of the mechanical properties of fiber and matrix. E stands for Young's modulus, $\mu$ for shear modulus and $\nu$ for Poisson's ratio.

\begin{tabular}{cccc} 
Material & $E[G P a]$ & $\mu[G P a]$ & $\nu[-]$ \\
\hline Glass fiber & 70.0 & 29.2 & 0.2 \\
Epoxy & 3.5 & 1.25 & 0.4
\end{tabular}

185 
are listed in Table 1

\subsection{Validation of the model}

The model is validated in Fig. 5 against the results reported in [39, 31, obtained with the Boundary Element Method (BEM) for a single fiber with a symmetric debond placed in an infinite matrix. This situation is modeled using the $1 \times 1-$ free RVE with $V_{f}=0.0079 \%$, which corresponds to a RUC's length and height of respectively $\sim 200 R_{f}$ and $\sim 100 R_{f}$.

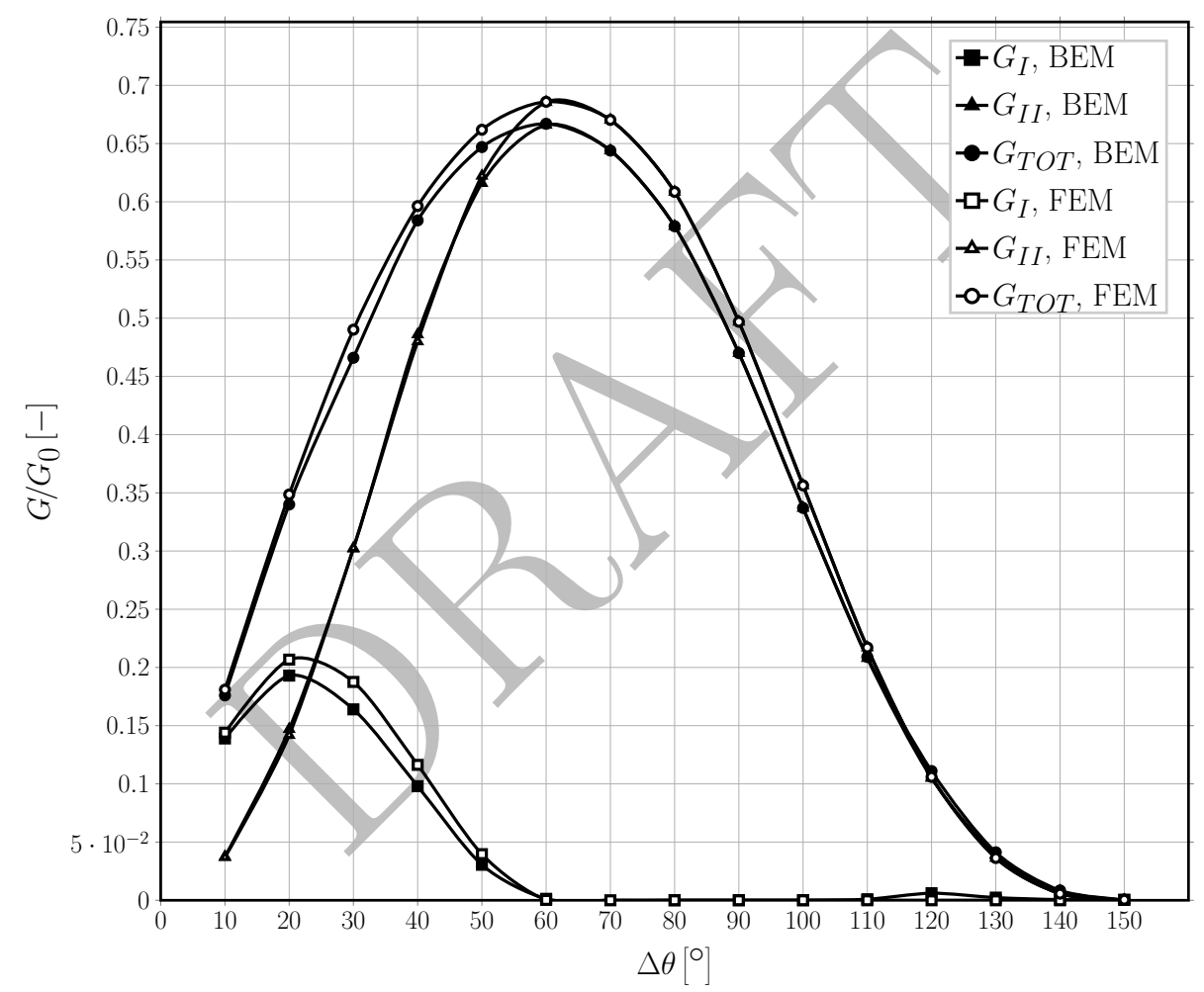

Figure 5: Validation of the single fiber model for the infinite matrix case with respect to the BEM solution in 31.

To allow for a comparison, the results are normalized following [31] with respect to a reference Energy Release Rate $G_{0}$ defined as

$$
G_{0}=\frac{1+k_{m}}{8 \mu_{m}} \sigma_{0}^{2} \pi R_{f}
$$


where $\mu$ is the shear modulus, $k$ is the Kolosov's constant defined as $3-4 \nu$ for plane strain conditions, $R_{f}$ is the fiber radius and the index $m$ refers to the properties of the matrix. $\sigma_{0}$ is the stress at the boundary, computed as the average of the stress extracted at each boundary node along the right side (arithmetic average as nodes are equispaced by design along both the left and right sides). The agreement is good: the difference between the BEM solution, which is considered more accurate, and the FEM solution does not exceed $5 \%$. The ERRs' maxima are in the same positions and the size of the contact zone is the same. Nevertheless, an analysis of phenomena leading to less than $5 \%$ differences in ERR would not be reliable and, therefore, it is not recommended.

\section{Results \& Discussion}

\subsection{Effect of Fiber Volume Fraction}

As shown in Figs. 6 and 7, respectively for Mode I and Mode II, the fiber content has a drastic effect on the Energy Release Rate at the tip of the fiber/matrix the fiber content. For Mode I, Fig. 6, the maximum value of the ERR increases by $\sim 5.2$ times when $V_{f}$ changes from $30 \%$ to $65 \%$. The debond's angular size for which the peak value occurs remains unchanged at $20^{\circ}$, but for $V_{f}=60 \%$ 


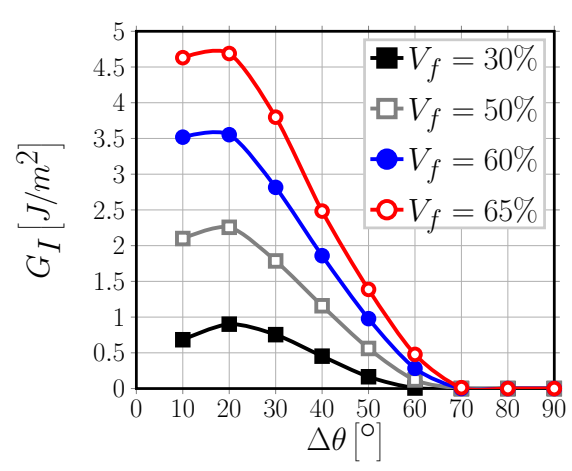

(a) Model $11 \times 11-$ free.

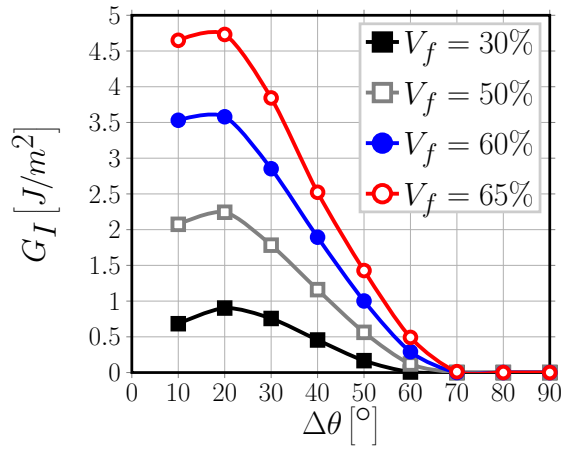

(b) Model $21 \times 21-$ free.

Figure 6: A view of the effect of fiber volume fraction on Mode I ERR in two exemplificative models, subject to an applied transverse strain $\varepsilon_{x}$ of $1 \%$.

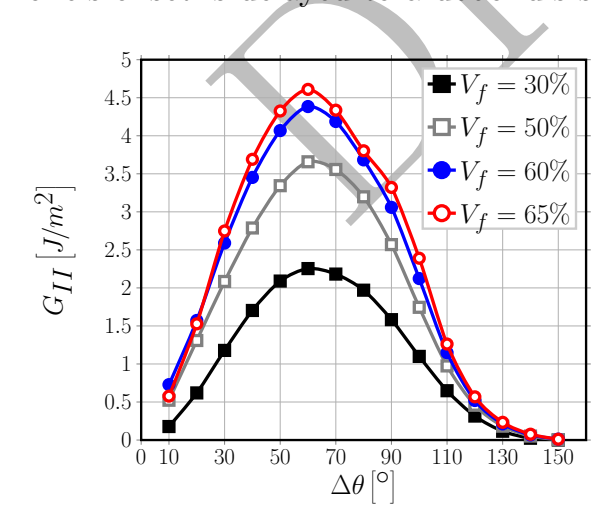

(a) Model $11 \times 11-$ free.

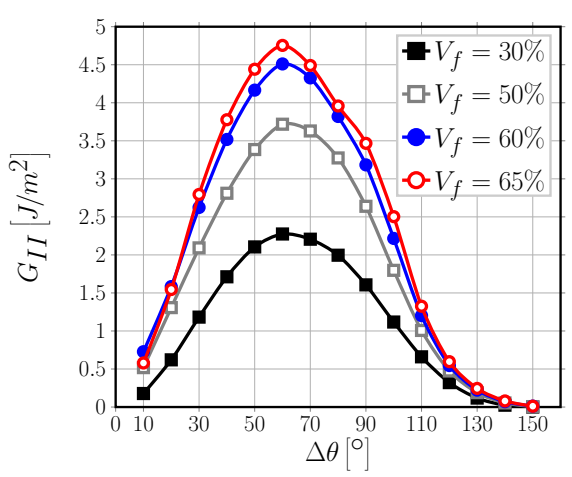

(b) Model $21 \times 21-$ free.

Figure 7: A view of the effect of fiber volume fraction on Mode II ERR in two exemplificative models, subject to an applied transverse strain $\varepsilon_{x}$ of $1 \%$. 
For Mode II, Fig. 7, there is a distinct maximum in the curve and its shape does not depend on the fiber content. The maximum value of the ERR increases by $\sim 2.1$ times when $V_{f}$ changes from $30 \%$ to $65 \%$. The effect is thus similar to Mode I, but with a significantly lower magnitude. Similar to Mode I, the debond's size for which the peak value of Mode II occurs remains unchanged, at $60^{\circ}$. It is worthwhile to notice that the ratio of Mode II to Mode I peak values is $\frac{\max \left(G_{I I}\right)}{\max \left(G_{I}\right)} \sim \frac{2.2}{0.9} \sim 2.4$ for $V_{f}=30 \%$, while it is $\sim \frac{4.7}{4.7} \sim 1$ for $V_{f}=65 \%$.

The general increasing trends observed in Figs. 6 and 7 are related to the fact that, given that the global and local $V_{f}$ are everywhere identical in the models presented, an increase in fiber content corresponds to a decrease in the average distance between fibers. Thus, the distances for the decay of the local stress and strain fields in the matrix domain become shorter, leading to higher stresses in general and causing higher values at the crack tip. The difference in relative magnitude between Mode I and Mode II and the delay in the contact zone's onset are instead due to the interplay between two different mechanisms, both caused by the ordered microstructural arrangement of the model. In the models considered, a fully bonded fiber is always placed along the horizontal direction, aligned with the partially debonded fiber and exactly in front of the debond. By increasing $V_{f}$, the former moves closer to the latter and for small debonds this causes a magnification of the $\mathrm{x}$-strain at the crack tip. For small debonds $\left(\leq 20^{\circ}-30^{\circ}\right)$ in fact, the crack tip is approximately normal to the $x$-direction and thus an increase in $\varepsilon_{x}$ causes an increase in $G_{I}$. On the other hand, for large debonds $\left(\geq 70^{\circ}-80^{\circ}\right)$ the crack growth direction is almost aligned with the $x$-axis, thus a magnification in the $x$-strain translates into an increase of Mode II ERR. However, this increasing effect on $G_{I I}$ is partially counteracted by the presence of a fully bonded fiber on top of the debonded fiber and aligned with it. As fibers are more rigid than the surrounding matrix, the presence of the former will restrain horizontal displacements, thus hampering strong increases in $G_{I I}$ for large debonds. Furthermore, due to the mismatch in the Poisson's ratios, the fully bonded fiber placed above generates an upward-directed component of the vertical displacement field in the matrix, which tends to open the debond 
and causes the delay in the contact zone's onset. The interplay between these mechanisms is governed by the average inter-fiber distance and, in turn, by the fiber volume fraction.

These observations are in agreement with the results reported in [31], where the effect on the ERR of a partially debonded fiber of two fully bonded nearby fibers, placed symmetrically with respect to the loading direction, is studied for different angular positions (denoted as $\theta_{2}$ ) and radial distances in a model with an effectively infinite matrix $\left(V_{f} \sim 0.09 \%\right)$. The effect of the former is studied for a constant value of the radial distance between the debonded and bonded fibers, which corresponds to a local $V_{f}^{\text {local }}$ of $\sim 62 \%$ assuming hexagonal packing. They report an increase in both Mode I and Mode II ERR with respect to the single fiber case when the two fibers are placed at an angle of respectively $285 \pm 25^{\circ}, \pm 30^{\circ}, \pm 140^{\circ}, \pm 150^{\circ}, \pm 155^{\circ}$, i.e. closest to the loading direction. Notice that for $\pm 25^{\circ}$ and $\pm 155^{\circ}$ the two fully bonded fibers are almost in contact, with an inter-fiber distance of $\sim 0.04$ times their radius. This result confirms the considerations made in the previous paragraph about the $x$-strain magnification caused by the presence of fully bonded fibers along the loading direction. The effect is further analyzed and discussed in Sec. 3.2 and Sec. 3.4 In the range $\pm 40^{\circ}- \pm 130^{\circ}$ instead, the presence of the other fibers causes a reduction of the ERR and, particularly in the range $80^{\circ}-120^{\circ}$, results are very close and almost insensitive to variations in $\theta_{2}$, which supports the previous conclusion about the effect of a fully bonded fiber on top the partially debonded one. This effect is treated in more detail in Sec. 3.3 .

Comparing the results from [31 with those presented in this paper, an hypothesis can be furthermore formulated about the robustness of the results of the present article with respect to deviations in fiber position: it seems reasonable to assume a tolerance to deviations of max. $\pm 30^{\circ}$ with respect to the loading direction and of max. $\pm 20^{\circ}$ with respect to the through-the-thickness direction. The effect of the local fiber content is also investigated in 31, by changing the radial distance between the partially debonded fiber and the fully bonded ones. They observe that the further the fully bonded fibers are placed from the 
central one, i.e. the lower the local $V_{f}$, the lower is their effect on the ERR.

periodic solution.

\subsection{Interaction between debonds in UD composites with a single row of fibers}

The interaction of debonds appearing at regular intervals in an ultra-thin UD composite with a single row of fibers is studied for Mode I (Fig. 8) and Mode and $9 \mathrm{~b}$. The models treated are $3 \times 1-$ free, $5 \times 1-$ free, $7 \times 1-$ free, $11 \times 1-$ free, $21 \times 1-$ free, $101 \times 1-$ free and $201 \times 1-$ free, corresponding respectively to a debond every $3^{r d}, 5^{t h}, 7^{t h}, 11^{\text {th }}, 21^{\text {st }}, 101^{\text {st }}$ and $201^{\text {st }}$ fiber 
(Fig. 1a). Given that the upper surface of the UD row is left free, the interaction

the results of this section are thus the most conservative in terms of debond's growth: the ERRs should be the largest. The effect is enhanced in composites with high $V_{f}$ and especially for $G_{I I}$ : at $V_{f}=60 \%$ the highest $G_{I I}$ value for the $201 \times 1-$ free composite in Fig. $9 \mathrm{~b}$ is more than 3 times higher than the $G_{I I}$ value value for the $21 \times 21-$ free composite in Fig. $7 \mathrm{~b}$, Even the maximum is shifted to larger angles. The $G_{I}$ value is for some cases only $30 \%$ higher.

From both Fig. 8 and Fig. 9 , it can be seen that the presence of a debond close to the analyzed debond decreases the strain magnification effect discussed in Sec. 3.1 and thus reduces the value of the ERR. This phenomenon is called "crack shielding" [26].

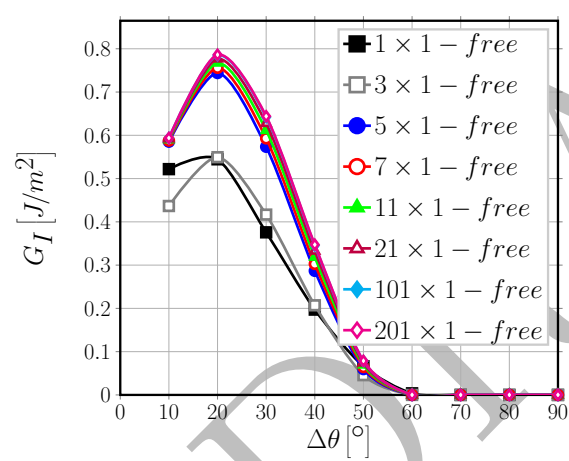

(a) $V_{f}=30 \%$.

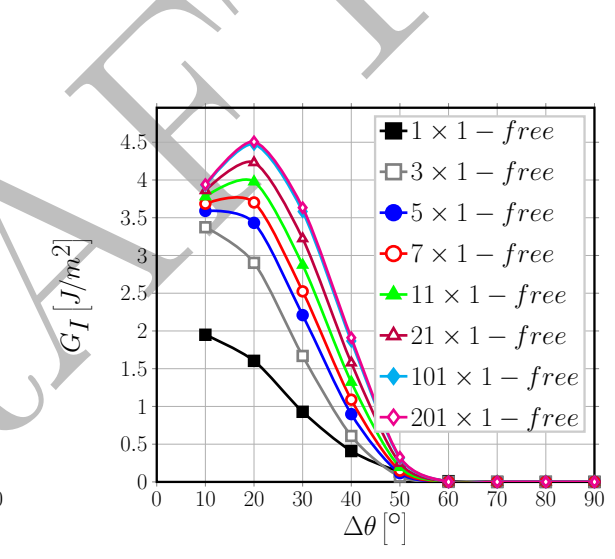

(b) $V_{f}=60 \%$.

Figure 8: Effect of the interaction between debonds appearing at regular intervals on Mode I ERR in an UD with a single row of fibers at different levels of fiber volume fraction $V_{f}$, subject to an applied transverse strain $\varepsilon_{x}$ of $1 \%$.

For Mode I, the presence of a free surface, and inversely the absence of a fully bonded fiber along the vertical direction, implies the absence of the counteracting upward-oriented vertical component of the displacement field due to the mismatch in Poisson's ratios. This in turn translates into the constancy of the value of $\Delta \theta$ corresponding to contact zone's onset, always equal to $60^{\circ}$. For $V_{f}=30 \%$, Mode I is reduced when the spacing between debonds (in terms 
of number of fully bonded fibers between them in our models) decreases, but the magnitude of change is significant only in the range when the spacing is reduced from a debond every $5^{\text {th }}$ fiber to one every $3^{\text {rd }}$. For comparison, the difference of peak $G_{I}$ values for $V_{f}=30 \%$ between $5 \times 1-$ free and $3 \times 1-$ free is $\sim 0.2 \frac{J}{m^{2}}$ (around $30 \%$ of the lower value), while between $201 \times 1-$ free and $5 \times 1-$ free is $\sim 0.05 \frac{\mathrm{J}}{\mathrm{m}^{2}}$ (around $7 \%$ of the lower value). A similar observation can be made for $V_{f}=60 \%$, but for larger spacings: no difference can be seen between the case of a debond placed every $101^{\text {th }}$ and every $201^{\text {th }}$ fiber. These observations suggest the existence of characteristic distance dependent on the fiber volume fraction which governs the interaction between debonds: in low $V_{f}$ composites $\left(V_{f}=30 \%\right)$ the convergence to a non-interactive solution is faster (less interaction between debonded fibers in neighboring RUCs).

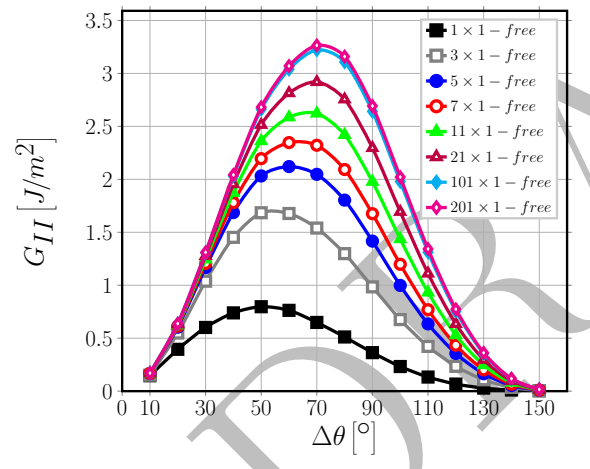

(a) $V_{f}=30 \%$.

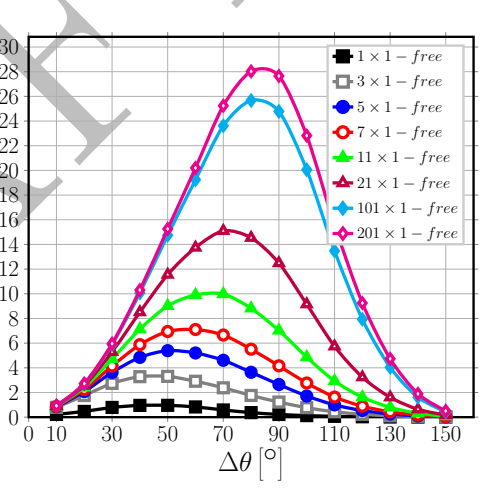

(b) $V_{f}=60 \%$.

Figure 9: Effect of the interaction between debonds appearing at regular intervals on Mode II ERR in an UD with a single row of fibers at different levels of fiber volume fraction $V_{f}$, subject to an applied transverse strain $\varepsilon_{x}$ of $1 \%$.

Without costraint on the upper surface, the strain magnification effect creates a larger displacement gap in the $x$-direction, which increases Mode II for larger debonds. When debonds are far apart, the series of rigid elements in the ultra-thin composite row (constituted by fully bonded fibers and their surrounding matrix) creates higher $x$-strains than in average in the element with the debonded fiber, which in turn generates higher tangential displacements at the 
ber of rigid elements between them), the strain concentration in the debonded element is more similar to the applied strain (the magnification is reduced) and the tangential displacement component at the crack tip decreases for large $\Delta \theta$. This is the mechanism behind the change in the value of $\Delta \theta$ for which the peak from the higher to the smaller spacing of debonds. Differently from Mode I, the presence of a characteristic distance is harder to establish. For $V_{f}=30 \%$ (Fig. 9a), it seems reasonable to establish it at around 100 fully bonded fibers between each debond. For $V_{f}=60 \%$ (Fig. 9b), the difference between models $101 \times 1-$ free and $201 \times 1-$ free is still sizable, thus preventing the establishment of such characteristic distance. It is possible to observe, however, that the change between $101 \times 1-$ free and $201 \times 1-$ free is significantly smaller than between $21 \times 1-$ free and $101 \times 1-$ free $\left(2\left[\frac{J}{m^{2}}\right]\right.$ vs $\left.11\left[\frac{J}{m^{2}}\right]\right)$, thus suggesting the existence of the characteristic distance outside the range studied. the central row with all fibers partially debonded is studied for Mode I (Fig. 10 and Mode II (Fig. 11) and fiber content equal to 30\% (Figs. 10a and 11a) and $60 \%$ (Figs. $10 \mathrm{~b}$ and $11 \mathrm{~b}$. The models treated are $1 \times 3-$ free, $1 \times 5-$ free, $1 \times 7-$ free, $1 \times 11-$ free, $1 \times 21-$ free, $1 \times 101-$ free and $1 \times 201-$ free, 395 corresponding to a UD composite with respectively 3, 5, 7, 11, 21, 101 and 201 rows of fibers (Fig. 2a).

The results shown strengthen the arguments made in Sec. 3.1 and Sec. 3.2 It can, in fact, be seen in Fig. 10 that an increasing number of bonded fiber rows across the thickness delays the onset of the contact zone to a debond of $70^{\circ}$ in 


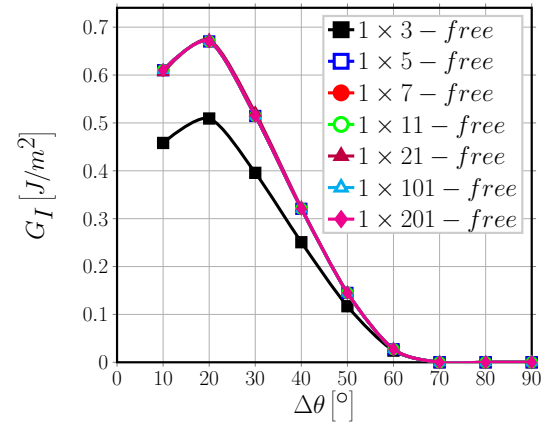

(a) $V_{f}=30 \%$.

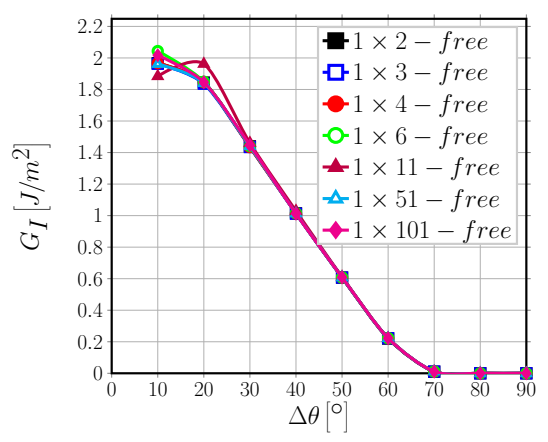

(b) $V_{f}=60 \%$.

Figure 10: Influence of rows of fully bonded fibers on debond's growth in Mode I ERR in a centrally located row of debonded fibers at different levels of fiber volume fraction $V_{f}$, subject to an applied transverse strain $\varepsilon_{x}$ of $1 \%$.

size, due to the introduction of an additional positive component of the vertical displacement which translates into an opening displacement at the debond's tip. Comparing Fig. 9b with Fig. 11b, we observe that the presence of bonded fiber rows significantly reduce the $G_{I I}$ and its maximum is shifted back to $60^{\circ}$, thus confirming the hypothesis in Section 3.2 that the absence of $G_{I I}$ convergence with the increasing distance in a single-row composite is caused more by the free surface than by the interaction between debonds.

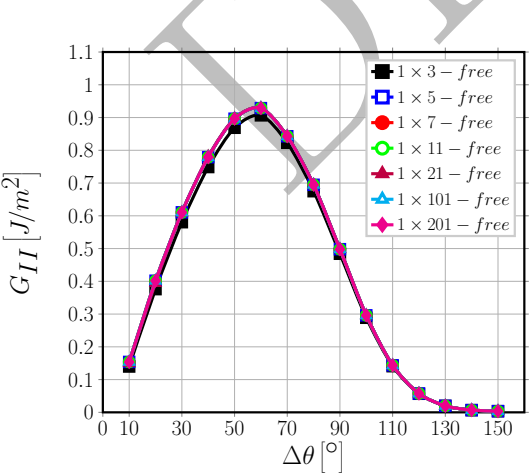

(a) $V_{f}=30 \%$.

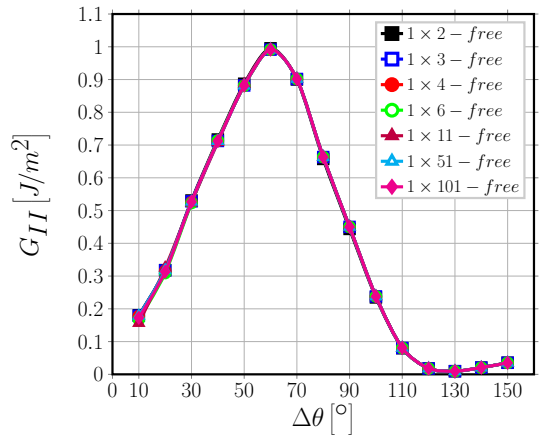

(b) $V_{f}=60 \%$.

Figure 11: Influence of rows of fully bonded fibers on debond's growth in Mode II ERR in a centrally located row of debonded fibers at different levels of fiber volume fraction $V_{f}$, subject to an applied transverse strain $\varepsilon_{x}$ of $1 \%$. 
The results of both Mode I and Mode II show that the introduction of an increasing number of fully bonded fiber rows doesn't change the ERR calculated at the crack tip after adding more than one row (the convergence is very fast).

interplay is further modulated by the fiber content. Observing Fig. 12, it is possibe to note how the free surface interaction decays fast: the presence of 5 fiber rows across the thickness is already sufficient to prevent any significant effect of additional fiber rows on the ERR of a debond in the central row.

The results in Fig. 13 show instead the effect of increasing the distance between two consecutive debonds in the central row of a UD composite of given 


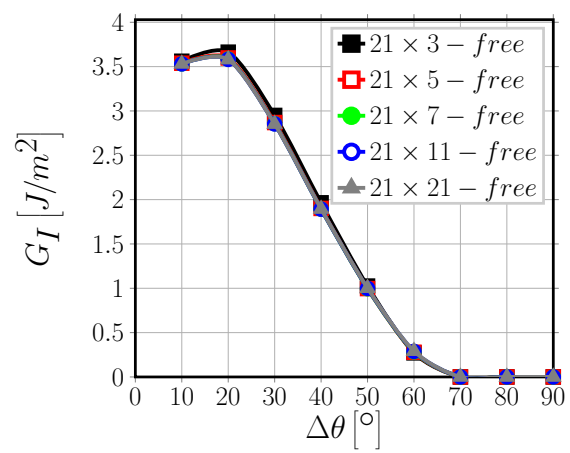

(a) $G_{I}$.

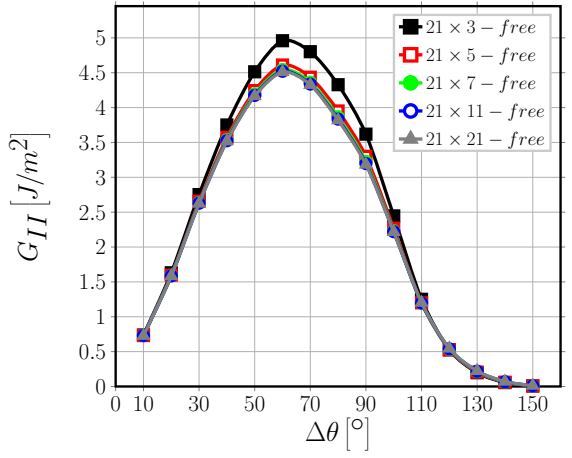

(b) $G_{I I}$.

Figure 12: Effect on Mode I and Mode II ERR of the presence of an increasing number of rows of fully bonded fibers in UD composites with debonds appearing every $10^{\text {th }}$ fiber (model $21 \times k-$ free $) . V_{f}=60 \%$ and $\varepsilon_{x}=1 \%$.

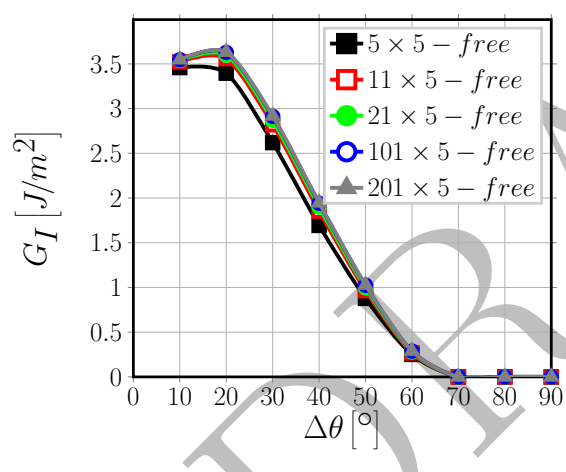

(a) $G_{I}$.

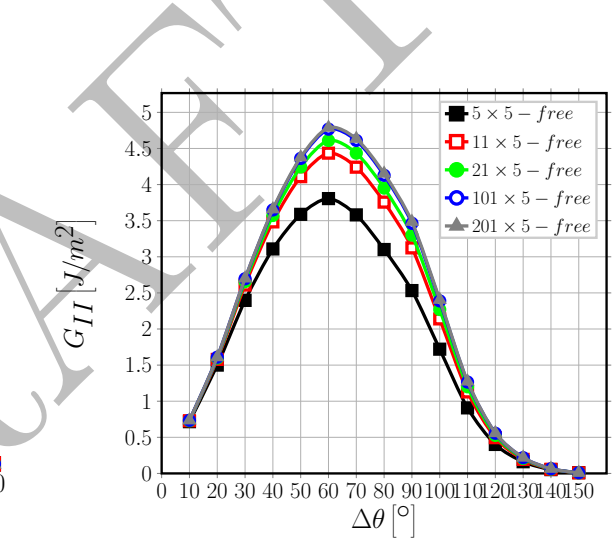

(b) $G_{I I}$.

Figure 13: Effect on Mode I and Mode II ERR of increasing the spacing between debonds appearing in the central row of fibers in a UD composite with a fixed number of rows across the thickness. $V_{f}=60 \%, k=5$ and $\varepsilon_{x}=1 \%$.

thickness. In agreement with the observations of Section 3.2 increasing the distance between debonds (measured in terms of fully bonded fibers between them) causes an increase in the ERR in both Mode I and Mode II. For both

Mode I and Mode II, it is possible to observe the existence of a characteristic distance which defines the limit between the interactive and the non-interactive solution. Furthermore, comparing Figure $13 \mathrm{a}$ and $13 \mathrm{~b}$, it is possible to notice 
that Mode I is less sensitive than Mode II to the horizontal spacing of debonds.

\subsection{Comparison with the single fiber model with equivalent boundary conditions} damaged state of the composite, i.e. the state in which all fibers have debonds The $1 \times 1-$ free model represents an ultra-thin UD composite with a single row of partially debonded fibers. The $1 \times 1$-coupling model, where the displacement coupling is used to enforce periodic boundary conditions, represents an infinite due to the Poisson's effect and thus favors Mode I and reduces Mode II. This 


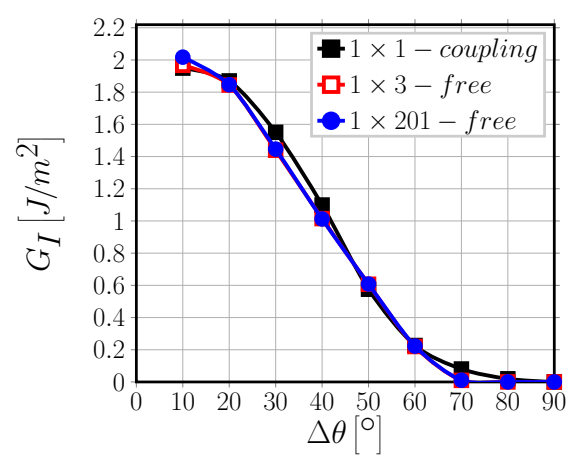

(a) $G_{I}$.

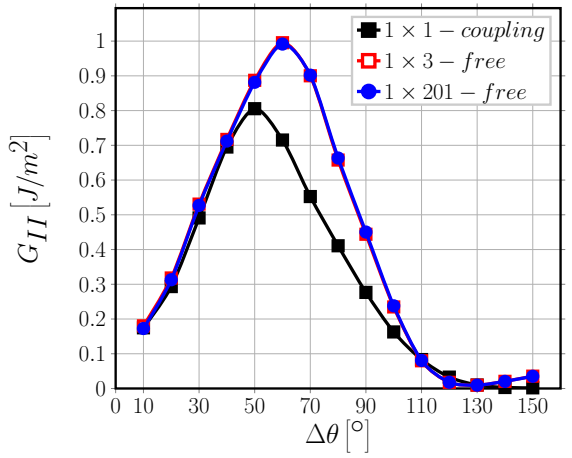

(b) $G_{I I}$.

Figure 14: Comparison of the ERR between the single fiber model with coupling conditions along the upper boundary and the $1 \times k-$ free model. $V_{f}=60 \%$ and $\varepsilon_{x}=1 \%$.

translates into the delay in the appearance of the contact zone, particularly evident in Fig. 14a

\section{Conclusions \& Outlook}

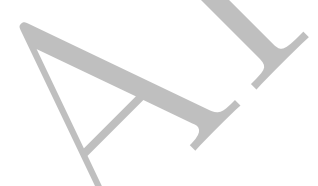

Several models of Repeating Unit Cell, representative of different microstructural arrangements of a unidirectional (UD) composite, have been studied in order to investigate the effect on fiber/matrix interface crack growth of the presence of partially debonded and/or fully bonded fibers. Regular microstructures based on square-packing arrangements of fibers have been loaded in transverse tension, with debonds appearing in the central row of fibers at regular intervals measured in terms of number of fully bonded fibers between them. This central row is embedded in-between a varying number of rows with perfectly bonded fibers. The surface of the composite is either traction-free or with imposed vertical displacement constraint imitating a periodic structure in the composite thickness direction.

The fiber volume fraction is the same everywhere and the fiber distribution is uniform by design, which establishes a direct relationship between fiber content and inter-fiber distance. The main conclusions of this work are summarized here. 
1. With a decreasing number of fully bonded fibers between two partially debonded fibers in the central row, the ERR decreases. It seems to exist a characteristic distance between debonds which defines the transition to a non-interactive solution. However, this distance depends on the number of perfectly bonded fiber rows surrounding the central row.

2. The presence of a free surface close to the debond leads to higher Mode I and Mode II ERRs and a shift of the peak $G$ values to larger debonds.

3. The presence of fibers (fully or partially bonded) in the composite thickness direction, along the same vertical line as the analyzed central fiber, appears to have a restraining effect on both $G_{I}$ and $G_{I I}$. The free composite surface effect on the ERR decays very fast: adding more than 2 fully bonded fibers below and above the central row leads to stable constant values of ERR.

4. The presence of a debond in the fiber above the central partially debonded one only delays the appearance of the contact zone, while no significant effect on the ERR has been observed.

5. Increasing the fiber content (decreasing the inter-fiber distance), magnifies in general the effects described in the previous points.

6. The results and conclusions presented agree well with previous observations reported in the literature 31, 34. A mechanical explanation of the observed trends has been presented based on the mismatch in elastic properties, particularly Poisson's ratios, and the positions of fibers and debonds with respect to the loading direction.

\section{Acknowledgements}

Luca Di Stasio gratefully acknowledges the support of the European School of Materials (EUSMAT) through the DocMASE Doctoral Programme and the European Commission through the Erasmus Mundus Programme. 


\section{References}

[1] D. A. McCarville, J. C. Guzman, A. K. Dillon, J. R. Jackson, J. O. Birkland, 3.5 Design, Manufacture and Test of Cryotank Components, Elsevier, 2018, pp. 153-179. doi:10.1016/b978-0-12-803581-8.09958-6.

[2] Y. H. N. Kim, S. Ko, W.-S. Lay, J. Tian, P. Chang, S. U. Thielk, H.-J. Bang, J. Yang, Effects of shallow biangle, thin-ply laminates on structural performance of composite wings, AIAA Journal 55 (6) (2017) 2086-2092. doi:10.2514/1.j055465.

[3] A. Kopp, S. Stappert, D. Mattsson, K. Olofsson, E. Marklund, G. Kurth, E. Mooij, E. Roorda, The aurora space launcher concept, CEAS Space Journal 10 (2) (2017) 167-187. doi:10.1007/s12567-017-0184-2.

[4] K. Kawabe, S. Tomoda, T. Matsuo, A pneumatic process for spreading reinforcing fiber tow, in: Proceedings of the $42^{\text {nd }}$ International SAMPE Symposium and Exhibition, SAMPE, pp. 65-76.

[5] K. Kawabe, New spreading technology for carbon fiber tow and its application to composite materials, Sen'i Gakkaishi 64 (8) (2008) 262-267. doi:10.2115/fiber.64.p_262.

[6] K. Kawabe, H. Sasayama, S. Tomoda, New carbon fiber tow-spread technology and applications to advanced composite materials, SAMPE Journal 45 (2) (2008) 6-17.

[7] H. Sasayama, K. Kawabe, S. Tomoda, I. Ohsawa, K. Kageyama, N. Ogata, Effect of lamina thickness on first ply failure in multidirectionally laminated composites, in: Proceedings of the $8^{\text {th }}$ Japan SAMPE Symposium, SAMPE, 2003.

[8] S. Sihn, R. Kim, K. Kawabe, S. Tsai, Experimental studies of thin-ply laminated composites, Composites Science and Technology 67 (6) (2007) 996-1008. doi:10.1016/j.compscitech.2006.06.008. 
[9] T. Yokozeki, Y. Aoki, T. Ogasawara, Experimental characterization of strength and damage resistance properties of thin-ply carbon fiber/toughened epoxy laminates, Composite Structures 82 (3) (2008) 382389. doi:10.1016/j.compstruct.2007.01.015.

[10] T. Yokozeki, A. Kuroda, A. Yoshimura, T. Ogasawara, T. Aoki, Damage characterization in thin-ply composite laminates under out-of-plane

n transverse loadings, Composite Structures 93 (1) (2010) 49-57. doi: $10.1016 /$ j.compstruct. 2010.06 .016

[11] A. Arteiro, G. Catalanotti, J. Xavier, P. Camanho, Large damage capability of non-crimp fabric thin-ply laminates, Composites Part A: Applied Science and Manufacturing 63 (2014) 110-122. doi:10.1016/j.compositesa. 2014.04 .002

[12] R. Amacher, J. Cugnoni, J. Botsis, L. Sorensen, W. Smith, C. Dransfeld, Thin ply composites: Experimental characterization and modeling of size1. effects, Composites Science and Technology 101 (2014) 121-132. doi:10. $1016 / \mathrm{j}$.compscitech 2014.06 .027 .

[13] J. Cugnoni, R. Amacher, S. Kohler, J. Brunner, E. Kramer, C. Dransfeld, W. Smith, K. Scobbie, L. Sorensen, J. Botsis, Towards aerospace grade thin-ply composites: Effect of ply thickness, fibre, matrix and interlayer toughening on strength and damage tolerance, Composites Science and 565 \ Technology 168 (2018) 467-477. doi:10.1016/j.compscitech.2018.08. 037.

[14] H. Saito, H. Takeuchi, I. Kimpara, Experimental evaluation of the damage growth restraining in $90^{\circ}$ layer of thin-ply cfrp cross-ply laminates,

口 Advanced Composite Materials 21 (1) (2012) 57-66. doi:10.1163/ $570 \quad 156855112 \times 629522$.

[15] K. W. Garrett, J. E. Bailey, Multiple transverse fracture in $90^{\circ}$ cross-ply 
laminates of a glass fibre-reinforced polyester, Journal of Materials Science 12 (1) (1977) 157-168. doi:10.1007/bf00738481.

[16] A. Parvizi, J. E. Bailey, On multiple transverse cracking in glass fibre epoxy cross-ply laminates, Journal of Materials Science 13 (10) (1978) 2131-2136. doi:10.1007/bf00541666.

[17] A. Parvizi, K. W. Garrett, J. E. Bailey, Constrained cracking in glass fibrereinforced epoxy cross-ply laminates, Journal of Materials Science 13 (1) (1978) 195-201. doi:10.1007/bf00739291.

[18] J. E. Bailey, A. Parvizi, On fibre debonding effects and the mechanism of transverse-ply failure in cross-ply laminates of glass fibre/thermoset composites, Journal of Materials Science 16 (3) (1981) 649-659. doi: $10.1007 / \mathrm{bf} 02402782$

[19] J. E. Bailey, P. T. Curtis, A. Parvizi, On the transverse cracking and longitudinal splitting behaviour of glass and carbon fibre reinforced epoxy cross ply laminates and the effect of poisson and thermally generated strain, Proceedings of the Royal Society A: Mathematical, Physical and Engineering Sciences 366 (1727) (1979) 599-623. doi:10.1098/rspa.1979.0071.

[20] A. H. England, An arc crack around a circular elastic inclusion, Journal of Applied Mechanics 33 (3) (1966) 637. doi:10.1115/1.3625132.

[21] A. Perlman, G. Sih, Elastostatic problems of curvilinear cracks in bonded dissimilar materials, International Journal of Engineering Science 5 (11) (1967) 845-867. doi:10.1016/0020-7225(67)90009-2.

[22] M. Toya, A crack along the interface of a circular inclusion embedded in an infinite solid, Journal of the Mechanics and Physics of Solids 22 (5) (1974) 325-348. doi:10.1016/0022-5096(74)90002-7.

[23] M. Comninou, The interface crack, Journal of Applied Mechanics 44 (4) (1977) 631. doi:10.1115/1.3424148 
[24] F. París, J. C. Caño, J. Varna, The fiber-matrix interface crack - a numerical analysis using boundary elements, International Journal of Fracture 82 (1) (1996) 11-29. doi:10.1007/bf00017861.

[25] J. Varna, F. París, J. C.Caño, The effect of crack-face contact on fiber/matrix debonding in transverse tensile loading, Composites Science and Technology 57 (5) (1997) 523-532. doi:10.1016/s0266-3538(96) 00175-3

[26] I. García, V. Mantič, E. Graciani, Debonding at the fibre-matrix interface under remote transverse tension. one debond or two symmetric debonds?, European Journal of Mechanics - A/Solids 53 (2015) 75-88. doi:10.1016/ j.euromechsol.2015.02.007

[27] E. Correa, E. Gamstedt, F. París, V. Mantić, Effects of the presence of compression in transverse cyclic loading on fibre-matrix debonding in unidirectional composite plies, Composites Part A: Applied Science and Man-

口 ufacturing 38 (11) (2007) 2260-2269. doi:10.1016/j.compositesa.2006. 11.002

[28] E. Correa, V Mantič, F. París, Effect of thermal residual stresses on matrix failure under transverse tension at micromechanical level: A numerical and experimental analysis, Composites Science and Technology 71 (5) (2011) 622-629. doi:10.1016/j.compscitech.2010.12.027.

[29] E. Correa, F. París, V. Mantič, Effect of the presence of a secondary transverse load on the inter-fibre failure under tension, Engineering Fracture Mechanics 103 (2013) 174-189. doi:10.1016/j.engfracmech.2013.02.026.

[30] E. Correa, F. París, V. Mantič, Effect of a secondary transverse load on the inter-fibre failure under compression, Composites Part B: Engineering 65 (2014) 57-68. doi:10.1016/j.compositesb.2014.01.005

${ }_{625}$ [31] C. Sandino, E. Correa, F. París, Numerical analysis of the influence of a nearby fibre on the interface crack growth in composites under transverse 
[32] C. Sandino, E. Correa, F. París, Composite materials under transverse

[35] J. Varna, L. Q. Zhuang, A. Pupurs, Z. Ayadi, Growth and interaction of debonds in local clusters of fibers in unidirectional composites during

[

${ }_{45}^{6}$ [36] Simulia, Providence, RI, USA, ABAQUS/Standard User's Manual, Version $6.12(2012)$.

[37] R. Krueger, Virtual crack closure technique: History, approach, and applications, Applied Mechanics Reviews 57 (2) (2004) 109. doi:10.1115/1. 1595677

[38] J. R. Rice, A path independent integral and the approximate analysis of strain concentration by notches and cracks, Journal of Applied Mechanics 35 (2) (1968) 379. doi:10.1115/1.3601206. 
[39] F. París, E. Correa, V. Mantič, Kinking of transversal interface cracks between fiber and matrix, Journal of Applied Mechanics 74 (4) (2007) 703.

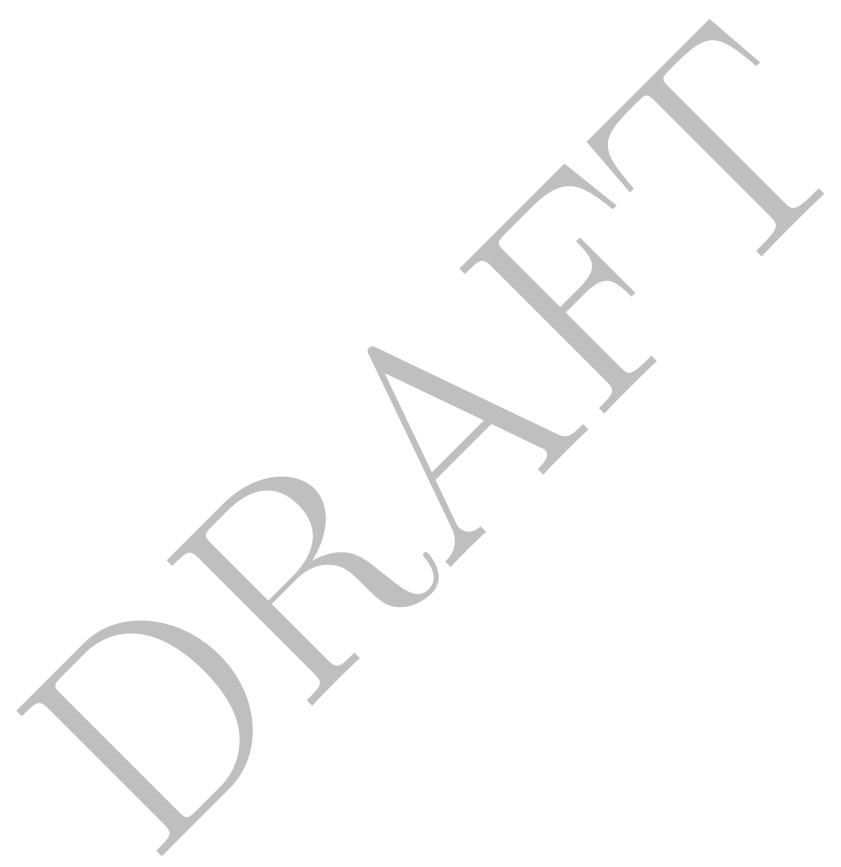

